\title{
Influence of estrous cycle and gestation on cardiovascular system of bitches
}

\author{
Vivian T. Almeida ${ }^{\mathrm{a}, *}$, Ricardo A.R. Uscategui ${ }^{\mathrm{a}}$, Aparecido A. Camacho ${ }^{\mathrm{a}}$, \\ Marlos G. Sousa ${ }^{b}$, Victor J.C. Santos ${ }^{a}$, Marjury C. Maronezi ${ }^{a}$, Wilter R.R. Vicente ${ }^{c}$, \\ Marcus A.R. Feliciano ${ }^{\text {d,e }}$ \\ ${ }^{a}$ Department of Veterinary Clinical and Surgery, Faculdade de Ciências Agrárias e Veterinária - UNESP, Câmpus Jaboticabal, Brazil \\ ${ }^{\mathrm{b}}$ Department of Veterinary Medicine, Universidade Federal do Paraná - UFPR, Câmpus Curitiba, Brazil \\ ${ }^{\mathrm{c}}$ Department of Animal Reproduction, Faculdade de Ciências Agrárias e Veterinária - UNESP, Câmpus Jaboticabal, Brazil \\ d Program of Post Graduate in Faculdade de Ciências Agrárias e Veterinária - UNESP, Câmpus Jaboticabal, Brazil \\ ${ }^{\text {e }}$ Sector of Diagnostic Imaging of Universidade Federal do Recôncavo da Bahia - UFRB, Brazil
}

\section{A R T I C L E I N F O}

\section{Keywords:}

Canine

Pregnant

Morphophysiology

Cardiac function

\begin{abstract}
A B S T R A C T
The purpose of this study was to evaluate the consequences of the estrous cycle and gestation on the cardiovascular system of bitches evaluated through echocardiographic assessment. Fifteen healthy pregnant bitches aged 2 to 6 years and weighing $8.8 \pm 2.5 \mathrm{~kg}$ were included in the study. Heart rate and blood pressure were clinically evaluated. M-mode, spectral, and tissue Doppler-echocardiography assessments were performed during the anestrous and estrous stages, every 15 days during pregnancy $(15,30,45$, and 60 days), and 45 days postpartum. The data for evaluated variables were submitted for statistical analysis. Heart rate $(P=0.286)$ and systolic blood pressure $(P=0.686)$ were not changed as a result of pregnancy or estrus, while ejection fraction $(P=0.0016)$ and fractional shortening $(P=0.00004)$ changed. The variables transmitral flow, isovolumetric relaxation time, aortic and pulmonary flow, and some variables related to myocardium movement obtained via tissue Doppler assessment varied $(P<0.05)$ among the reproductive periods studied. In conclusion, gestation resulted in changes in echocardiography variables, and consequently, on maternal hemodynamics, with myocardial contractility increasing during pregnancy, resulting in greater systolic efficiency and ventricular compliance.
\end{abstract}

\section{Introduction}

During gestation, the formation of a uteroplacental vascular bed promotes an increase in the compliance of blood vessels (Nautrup, 1998; Di Salvo et al., 2006; Blanco et al., 2009), with a consequent reduction in peripheral vascular resistance (PVR) and cardiac output (CO). These changes, associated with adaptations in the renin-angiotensin-aldosterone system, are responsible for the gestational plasma volume that culminates in volume overload. The heart adapts to these changed circulatory demands by becoming hypertrophic. Stroke volume increases, maximizing the supply of nutrients to tissues (Gilson et al., 1992; Blanco et al., 2011) so that the requirements for fetal development are met (Blanco et al., 2008; Eghbali et al., 2005).

Characterization of the cardiovascular system adaptations in pregnant bitches has been an object of studies in veterinary medicine, revealing the importance of these variables to myocardial contractility (systolic function) and cardiac output (Blanco et al.,

\footnotetext{
* Corresponding author at: via de acesso Prof. Paulo Donato Castellane s/n, 14884-900, Jaboticabal, São Paulo, Brazil.

E-mail address: vitalmeida21@hotmail.com (V.T. Almeida).
} 
2012; Souza et al., 2017). The paucity of information in this species provides opportunities for more detailed evaluation of the echocardiographic variables such as relaxation capacity and compliance of this organ (diastolic function) during the gestation of healthy bitches.

The most frequently used method for cardiovascular diastolic function evaluation is the transmitral flow velocity measurement assessment using Doppler echocardiography (Boon, 2011). The evaluation of this function with use of the Doppler technology becomes relevant because it allows for the identification of alterations in myocardial relaxation patterns that are associated with increases in preload volume (Chetboul et al., 2007).

Pregnant females have hemodynamic changes, and it is believed that tissue Doppler echocardiographic evaluations can be used to understand the details that involve cardiovascular adaptations during gestation. The objective of this study was, therefore, to characterize the consequences of changes during the estrous cycle and gestation on the cardiovascular system of healthy bitches through echocardiographic examination.

\section{Material and methods}

This study was approved by institutional Animal Ethics and Welfare Committee (protocol no 023950/14). Fifteen healthy bitches of different breeds, 2 to 6 years and weighing $8.8 \pm 2.5 \mathrm{~kg}$ were used and evaluated while in anestrus, estrus, every 15 days during pregnancy $(15,30,45$, and 60 days), and 45 days postpartum. To determine the phases of the estrous cycle, cytological evaluation was conducted (Feldman and Nelson 2003).

Gestational diagnosis was made at approximately 15 days of gestation by gestational vesicle detection, considering the first day from the natural mating as Day 0. An Acuson S2000 ${ }^{\circledR}$ (Siemens ${ }^{\circledast}$, Germany) with a multi-frequency linear transducer (9.0 MHz) was used for these observations. The gestational stage was confirmed according to the method described by Feliciano et al. (2015).

\subsection{Heart rate systolic blood pressure}

Heart rate was measured by thoracic auscultation and systolic blood pressure (SBP; $\mathrm{mmHg}$ ) was measured in triplicate using the Doppler method (Dv10 PLX/Microem ${ }^{\circledast}$ ). The bitches were maintained in right-side recumbency, an appropriate cuff (size 40 - $50 \%$ of limb circumference) was placed around the left thoracic limb above the carpus joint, and the Doppler sensor was positioned over the medial metacarpal artery (Mucha, 2001).

\subsection{Echocardiography}

The M-Mode, Doppler, and tissue Doppler echocardiography, were performed with the bitches in lateral recumbency using the ultrasonic device Acuson S2000. Measurements were taken according to Boon, (1998) over three consecutive estrous cycles and were analyzed by one trained expert.

The interventricular septum thickness in diastole (IVSd; $\mathrm{mm}$ ) and in systole (IVSs; $\mathrm{mm}$ ), left ventricular end diastolic (LVDd; mm) and end systolic (LVDs; mm) diameter, left ventricular free wall thickness in diastole (LVFWd; mm) and in systole (LVFWs; mm), ejection (EF), and shortening (FS) fractions, were measured in M-mode. These measurements were taken from the short axis of the left ventricle in the cordal plane, with the cursor aligned perpendicular to the interventricular septum and equidistant from the papillary muscles. Calculations of the systolic function were obtained using the Teichholz technique.

On a short axis, measurement of the relationship between the diameters of the left atrium and the aortic diameter (LA:Ao) were assessed using cardiac base imaging. In a plane directed to the cardiac base, the peak velocity of the pulmonary valve (PVVmáx) was measured, with the sampling volume positioned next to the pulmonary leaflets on the face opposite the pulmonary artery.

The five-chamber apical image was obtained through the left parasternal window. The cursor was aligned parallel to the aortic flow, with the sampling volume positioned next to the aortic leaflets on the face opposite to the aorta. From this, the peak velocity of the aortic valve (AVVmax) was measured.

The pulsed Doppler mitral flow velocity curves were used for analysis of diastolic function, as was the study of the mitral (septal and lateral) flow in an apical four-chamber image by tissue Doppler assessment (Fig. 1). To obtain the mitral flow, the volume sample pulsed Doppler was placed at the height of the commissural edges of the cusps with the mitral valve being open. The filter and gain were adjusted to the minimum possible values that were compatible with obtaining an adequate image of the flow spectrum. With this curve, peak velocities were obtained of the $\mathrm{E}$ wave $(\mathrm{E})$, corresponding to the early peak velocity of the trans-mitral flow, and of the A wave (A), corresponding to the late peak velocity of the trans-mitral flow; thus obtaining the ratio of E:A.

For measurement of the isovolumetric relaxation time (IVRT), the cursor of the pulsed Doppler was positioned equidistant between the outflow of the left ventricle and the trans-mitral flow, determining the time from the end of the trans-aortic flow to the beginning of rapid ventricular filling (E). The tissue Doppler evaluation was performed with a volume sample positioned on the septal (s) and lateral (lat) margins of the mitral annulus, allowing measurement of the peak velocity of the left myocardial wall during systole ( $\left.S^{\prime}\right)$. Early mitral annular diastolic movement - the rapid filling phase (E'), late mitral annular diastolic movement - the atrial contraction phase $\left(\mathrm{A}^{\prime}\right)$, and the $\mathrm{E}^{\prime}: \mathrm{A}^{\prime}$ and $\mathrm{E}: \mathrm{E}^{\prime}$ ratios were calculated. These were considered for the analysis of velocity measurements for each margin (septal and lateral). 


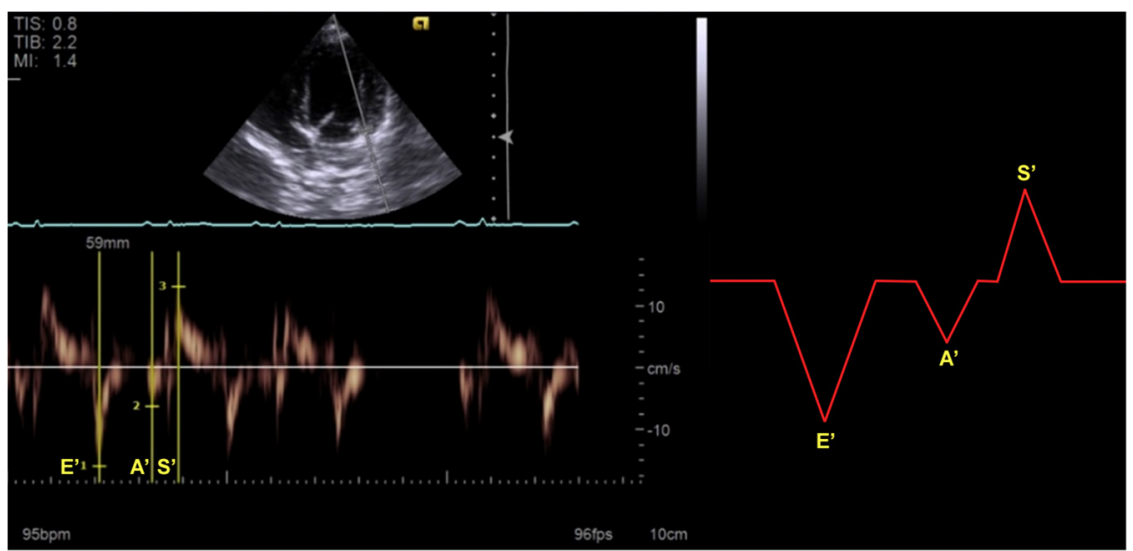

Fig. 1. A) Echocardiographic image with tissue Doppler in a longitudinal section. Four chamber view of a pregnant bitch, evaluating the lateral wall of the left ventricle B) schematic: E') early mitral annular diastolic movement; A') late mitral annular diastolic movement; $S^{\prime}$ ) peak velocity of the left myocardial wall measured during systole.

\subsection{Statistical analysis}

The R software was used for statistical analysis. Experimental design constituted blocks (bitches) randomized with subdivided parcel times (periods). Residual normality and homoscedasticity of variances were previously tested. Measures were compared between periods by repeated ANOVA, if results were significant, means were compared by Tukey test and polynomial contrasts (linear, quadratic and cubic). For variables where there was not a normal distribution, the Friedman test and Dunns post-test were applied. The level of significance was set at $P=0.05$.

\section{Results}

The mean gestational period was $61.0 \pm 2.5$ days, and the litter sizes ranged from 4 to 6 healthy pups. The bitches did not have any gestational or fetal delivery complications. The mean heart rate was $124.9 \pm 26.6$ beats per minute and SBP $127.5 \pm 15.1$ mm $\mathrm{Hg}$ and there were not differences in the values for these variables during the estrous cycle, gestation or postpartum $(P=0.2860$ and $P=0.6860$, respectively), and values were consistent with values previously reported for this species during gestation (Fig. 2).

For IVSd, IVSs, LVDd, LVDs, LVFWd, LVFWs, and LA:Ao, there was no variations $(P>0.05)$ in the values for these variables during the periods evaluated (Table 1). The values for measurements of the left ventricular chamber for all bitches were within the reference standard range when average body weights of $8.8 \pm 2.5 \mathrm{~kg}$ were considered.

The EF increased by $15 \%$ and FS by $20 \%$ from the $30^{\text {th }}$ day of gestation, with the peak value occurring at $45^{\text {th }}$ and $60^{\text {th }}$ day of gestation, respectively $(P<0.001)$. When the values during gestation were compared with those during estrus and anestrus, the effects on these variables can be explained by linear regression models $\left(R^{2}=0.65\right.$ and $R^{2}=0.68$, respectively). After 45 days from the day of parturition, only the FS returned to the values recorded in anestrus (Fig. 2).

$$
E F=62.5+0.16 \times \text { gestational dayFS }=31.9+0.14 \times \text { gestational day }
$$

When the values for the variables E, E:IVRT and E':A', E:E' (lat) were assessed there were no differences in the variations $(P>0.05)$ during the reproductive periods evaluated. The data for variables A, E:A, IVRT, PVVmáx, AVVmáx, E' (s) and E' (lat), A' (s) and $A^{\prime}$ (lat), $S^{\prime}(s)$ and $S^{\prime}$ (lat), and E: $E^{\prime}(s)$, however, varied when values during the various reproductive periods were assessed $(\mathrm{P}<0.05$; Table 2).

The A wave of the transmitral flow gradually increased until the $45^{\text {th }}$ day of gestation, when this value was $80 \%$ greater than the value when bitches were in anestrus. Subsequently, values decreased to those that were similar to those during estrus, however, remained greater during postpartum period than when bitches were in anestrus., This effect was explained by a quadratic regression model $\left(R^{2}=0.83\right.$; Fig. 2).

$$
A=0.7-0.0009 \times \text { gestational day }+0.00002 \times \text { gestational day }{ }^{2}
$$

The E:A ratio decreased by $50 \%$ during gestation to the $45^{\text {th }}$ day of gestation when compared to the ratio during anestrus. There was a subsequent increase in the ratio anestrus during postpartum period to those that were present during anestrus with this effect being explained by a cubic regression model $\left(R^{2}=0.78 ; P=0.001\right.$; Fig. 2).

$$
E: A=1.6+0.02 \times \text { gestational day }-0.001 \times \text { gestational day }{ }^{2}+0.00001 \times \text { gestational day }^{3}
$$

The IVRT was greater during anestrus, when compared to the measurements during estrus and the postpartum period. The IVRT increased during the first 15 days of gestation (10\%) and there was a subsequent decrease in values to where these were less than those during anestrus at the $45^{\text {th }}$ and $60^{\text {th }}$ days of gestation $(15 \%)$. This effect was explained by a cubic regression model $\left(R^{2}=0.38\right.$; 

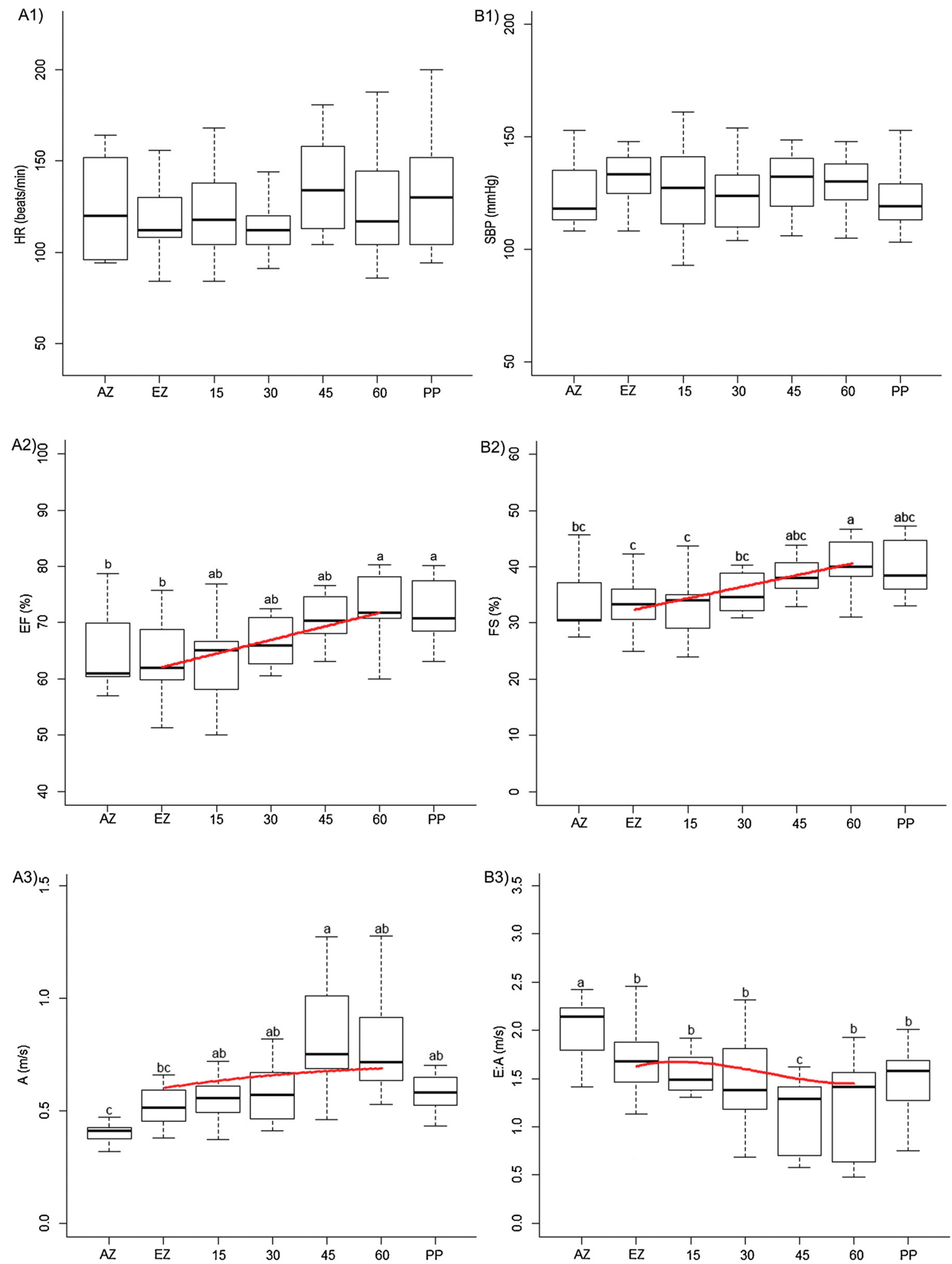

Fig. 2. Graphical representation of: A1) heart rate (HR); and B1) systolic blood pressure (SBP). A2) ejection fraction (EF); and B2) fractional shortening (FS). A3) late peak velocity of the trans-mitral flow (A); and B3) ratio of the early peak velocity of the trans-mitral flow: A (E: A). Evaluated in bitches during anestrus (AZ), estrus (EZ), pregnancy days (PD) 15, 30, 45 and 60, and 45 days postpartum (PP). Similar letters are indicative of a lack of differences ( $P>0.05$ ) and the red line indicates the regression model that estimates the changes in these variables during gestation. 
Table 1

Mean values and standard deviation of B-mode and M-mode variables during anestrus (AZ), estrus (EZ), pregnancy days ((PD) 15.30.45.60 days), and postpartum (45 days PP) in bitches

\begin{tabular}{|c|c|c|c|c|c|c|c|c|}
\hline Variables & Anestrus & Estrus & 15 (PD) & 30 (PD) & 45 (PD) & 60 (PD) & 45 (PP) & $P$ \\
\hline IVSs (mm) & $9.2 \pm 1.9$ & $11.2 \pm 2.0$ & $10.7 \pm 2.3$ & $10.5 \pm 1.6$ & $11.1 \pm 1.9$ & $9.9 \pm 1.8$ & $10.1 \pm 1.7$ & 0.073 \\
\hline IVSd (mm) & $6.9 \pm 0.8$ & $8.2 \pm 0.7$ & $7.9 \pm 1.1$ & $8 \pm 1.4$ & $8.5 \pm 1.6$ & $7.8 \pm 2.1$ & $7.7 \pm 1.5$ & 0.365 \\
\hline LVDs (mm) & $14.3 \pm 1.6$ & $10.7 \pm 2.3$ & $16.6 \pm 3.2$ & $17.1 \pm 2.6$ & $17.1 \pm 3.9$ & $15.3 \pm 3.2$ & $15.3 \pm 3.1$ & 0.131 \\
\hline LVDd (mm) & $21.9 \pm 3.6$ & $25.5 \pm 2.8$ & $25.1 \pm 4.1$ & $26.54 \pm 4.1$ & $27.1 \pm 4.6$ & $26 \pm 3.8$ & $25.1 \pm 5.8$ & 0.118 \\
\hline LVFWs (mm) & $9.9 \pm 1.8$ & $10.6 \pm 2.3$ & $11.0 \pm 2.5$ & $10.5 \pm 2.3$ & $10.8 \pm 1.8$ & $9.8 \pm 1.5$ & $10.5 \pm 1.8$ & 0.590 \\
\hline LVFWd (mm) & $7.8 \pm 1.5$ & $7.5 \pm 1.3$ & $8.1 \pm 2.0$ & $7.6 \pm 1.7$ & $7.8 \pm 1.8$ & $6.6 \pm 1.1$ & $7.4 \pm 1.4$ & 0.222 \\
\hline $\mathrm{EF}(\%)$ & $65.3 \pm 7.8^{\mathrm{B}}$ & $64.2 \pm 10.1^{\mathrm{B}}$ & $63 \pm 7.7^{\mathrm{AB}}$ & $66.5 \pm 4.6^{\mathrm{AB}}$ & $70.2 \pm 7.7^{\mathrm{AB}}$ & $72.7 \pm 6.2^{\mathrm{A}}$ & $72.1 \pm 5.6^{\mathrm{A}}$ & 0.001 \\
\hline FS (\%) & $34.1 \pm 6.3^{\mathrm{BC}}$ & $34.3 \pm 7.8^{C}$ & $32.8 \pm 5.5^{\mathrm{C}}$ & $35.4 \pm 3.6^{\mathrm{BC}}$ & $38.6 \pm 6.0^{\mathrm{ABC}}$ & $40.3 \pm 4.9^{\mathrm{A}}$ & $39.9 \pm 5^{\mathrm{AB}}$ & 0.001 \\
\hline LA: Ao (mm) & $1.3 \pm 0.2$ & $1.3 \pm 0.3$ & $1.3 \pm 0.2$ & $1.3 \pm 0.1$ & $1.3 \pm 0.2$ & $1.3 \pm 0.2$ & $1.3 \pm 0.2$ & 0.941 \\
\hline
\end{tabular}

IVSs, interventricular septum in systole; IVSd, interventricular septum in diastole; LVDs, left ventricular end systolic diameter; LVDd, left ventricular end diastolic diameter; LVFWs, left ventricular free wall in systole; LVFWd, left ventricular free wall in diastole; EF, ejection fraction; FS, shortening fraction; LA: Ao left atrium: aortic root ratio. Similar letters are indicative of a lack of differences $(P>0.05)$.

Table 2

Values (mean \pm SD or * median \pm IQR) obtained by spectral and tissue Doppler during anestrus, estrus, pregnancy days ((PD) 15, 30, 45, 60 days), and after delivery (45 Days PP) in bitches

\begin{tabular}{|c|c|c|c|c|c|c|c|c|}
\hline Variables & Anestrus & Estrus & 15 (PD) & 30 (PD) & 45 (PD) & 60 (PD) & 45 (PP) & $P$ \\
\hline $\mathrm{E}(\mathrm{m} / \mathrm{s})^{*}$ & $0,8 \pm 0,2$ & $0,9 \pm 0,1$ & $0,8 \pm 0,2$ & $0,8 \pm 0,1$ & $0,9 \pm 0,2$ & $1 \pm 0,3$ & $0,92 \pm 0,2$ & 0,137 \\
\hline $\mathrm{A}(\mathrm{m} / \mathrm{s})$ & $0,4 \pm 0,04^{\mathrm{C}}$ & $0,5 \pm 0,1^{\mathrm{BC}}$ & $0,6 \pm 0,2^{\mathrm{AB}}$ & $0,6 \pm 0,3^{\mathrm{AB}}$ & $0,8 \pm 0,2^{\mathrm{A}}$ & $0,7 \pm 0,2^{\mathrm{AB}}$ & $0,6 \pm 0,1^{\mathrm{AB}}$ & 0,001 \\
\hline $\mathrm{E}: \mathrm{A}(\mathrm{m} / \mathrm{s})^{*}$ & $2,1 \pm 0,04^{\mathrm{A}}$ & $1,7 \pm 0,4^{\mathrm{B}}$ & $1,5 \pm 0,3^{\mathrm{B}}$ & $1,4 \pm 0,6^{\mathrm{B}}$ & $1,3 \pm 0,7^{\mathrm{C}}$ & $1,4 \pm 0,8^{\mathrm{B}}$ & $1,6 \pm 0,4^{\mathrm{B}}$ & 0,001 \\
\hline IVRT (ms)* & $64,0 \pm 10,5^{\mathrm{A}}$ & $61 \pm 11,8^{\mathrm{BC}}$ & $71,2 \pm 12,8^{\mathrm{AB}}$ & $67,2 \pm 13,3^{\mathrm{AB}}$ & $57,2 \pm 10,7^{\mathrm{C}}$ & $55 \pm 8,7^{\mathrm{C}}$ & $61 \pm 12,7^{\mathrm{BC}}$ & 0,010 \\
\hline E:IVRT* & $0,013 \pm 0,01$ & $0,01 \pm 0,01$ & $0,01 \pm 0,01$ & $0,01 \pm 0,01$ & $0,01 \pm 0,01$ & $0,01 \pm 0,01$ & $0,01 \pm 0,01$ & 0,309 \\
\hline PVVmáx & $0,94 \pm 0,21^{\mathrm{C}}$ & $0,9 \pm 0,1^{\mathrm{BC}}$ & $0,9 \pm 0,2^{\mathrm{BC}}$ & $1 \pm 0,2^{\mathrm{ABC}}$ & $1,1 \pm 0,2^{\mathrm{A}}$ & $1,1 \pm 0,1^{\mathrm{AB}}$ & $1,1 \pm 0,2^{\mathrm{ABC}}$ & 0,001 \\
\hline AVVmáx & $1,2 \pm 0,3^{\mathrm{AB}}$ & $1,2 \pm 0,1^{\mathrm{AB}}$ & $1,1 \pm 0,3^{\mathrm{B}}$ & $1,1 \pm 0,2^{\mathrm{AB}}$ & $1,3 \pm 0,2^{\mathrm{AB}}$ & $1,3 \pm 0,4^{\mathrm{A}}$ & $1,3 \pm 0,4^{\mathrm{AB}}$ & 0,004 \\
\hline \multicolumn{9}{|c|}{ Septal wall (s) } \\
\hline $\mathrm{E}^{\prime}(\mathrm{m} / \mathrm{s})$ & $0,11 \pm 0,02^{\mathrm{A}}$ & $0,10 \pm 0,01^{\mathrm{A}}$ & $0,10 \pm 0,01^{\mathrm{AB}}$ & $0,10 \pm 0,01^{\mathrm{AB}}$ & $0,11 \pm 0,02^{\mathrm{B}}$ & $0,12 \pm 0,01^{\mathrm{C}}$ & $0,11 \pm 0,1^{\mathrm{AB}}$ & 0,036 \\
\hline$A^{\prime}(m / s)$ & $0,10 \pm 0,02^{\mathrm{A}}$ & $0,08 \pm 0,01^{\mathrm{B}}$ & $0,09 \pm 0,01^{\mathrm{AB}}$ & $0,09 \pm 0,01^{\mathrm{AB}}$ & $0,09 \pm 0,02^{\mathrm{AB}}$ & $0,09 \pm 0,01^{\mathrm{AB}}$ & $0,10 \pm 0,1^{\mathrm{AB}}$ & 0,031 \\
\hline $\mathrm{S}^{\prime}(\mathrm{m} / \mathrm{s})^{*}$ & $0,1 \pm 0,03^{\mathrm{A}}$ & $0,1 \pm 0,02^{\mathrm{ABC}}$ & $0,1 \pm 0,02^{\mathrm{C}}$ & $0,1 \pm 0,02^{\mathrm{BC}}$ & $0,1 \pm 0,03^{\mathrm{A}}$ & $0,1 \pm 0,02^{\mathrm{AB}}$ & $0,1 \pm 0,02^{\mathrm{AB}}$ & 0,012 \\
\hline$E^{\prime}: A^{\prime *}$ & $0,91 \pm 0,5$ & $1,4 \pm 0,1$ & $1,2 \pm 0,2$ & $1,2 \pm 0,2$ & $1,3 \pm 0,1$ & $1,3 \pm 0,3$ & $1,2 \pm 0,2$ & 0,140 \\
\hline $\mathrm{E}: \mathrm{E}^{\prime *}$ & $8,4 \pm 2,9^{A}$ & $8,1 \pm 1,9^{\mathrm{AB}}$ & $7,9 \pm 1,8^{\mathrm{AB}}$ & $7,7 \pm 1,9^{\mathrm{B}}$ & $7,4 \pm 1^{\mathrm{B}}$ & $7,6 \pm 2^{\mathrm{B}}$ & $8 \pm 1,5^{\mathrm{AB}}$ & 0,035 \\
\hline \multicolumn{9}{|c|}{ Lateral wall (lat) } \\
\hline$E^{\prime}(m / s)$ & $0,10 \pm 0,03^{B}$ & $0,12 \pm 0,02^{\mathrm{AB}}$ & $0,12 \pm 0,02^{\mathrm{AB}}$ & $0,11 \pm 0,01^{\mathrm{B}}$ & $0,14 \pm 0,03^{\mathrm{A}}$ & $0,14 \pm 0,02^{\mathrm{A}}$ & $0,13 \pm 0,02^{\mathrm{AB}}$ & 0,001 \\
\hline $\mathrm{A}^{\prime}(\mathrm{m} / \mathrm{s})^{*}$ & $0,08 \pm 0,04^{\mathrm{AB}}$ & $0,08 \pm 0,01^{\mathrm{B}}$ & $0,09 \pm 0,02^{\mathrm{B}}$ & $0,08 \pm 0,01^{\mathrm{B}}$ & $0,11 \pm 0,03^{\mathrm{A}}$ & $0,10 \pm 0,04^{\mathrm{AB}}$ & $0,10 \pm 0,01^{\mathrm{AB}}$ & 0,003 \\
\hline $\mathrm{S}^{\prime}(\mathrm{m} / \mathrm{s})$ & $0,098 \pm 0,02^{c}$ & $0,11 \pm 0,02^{\mathrm{ABC}}$ & $0,11 \pm 0,01^{\mathrm{BC}}$ & $0,10 \pm 0,02^{\mathrm{C}}$ & $0,13 \pm 0,02^{\mathrm{A}}$ & $0,14 \pm 0,02^{\mathrm{A}}$ & $0,13 \pm 0,03^{\mathrm{AB}}$ & 0,001 \\
\hline$E^{\prime}: A^{\prime *}$ & $1,2 \pm 0,4$ & $1,3 \pm 0,2$ & $1,3 \pm 0,3$ & $1,3 \pm 0,3$ & $1,3 \pm 0,2$ & $1,4 \pm 0,3$ & $1,4 \pm 0,3$ & 0,231 \\
\hline $\mathrm{E}: \mathrm{E}^{\prime *}$ & $7,2 \pm 1,9$ & $7,1 \pm 1,2$ & $7,1 \pm 2,1$ & $7,1 \pm 2,2$ & $6,9 \pm 1,3$ & $6,9 \pm 1,4$ & $7,1 \pm 2,2$ & 0,084 \\
\hline
\end{tabular}

A, late peak velocity of the trans-mitral flow; A', late mitral annular diastolic movement; E, early peak velocity of the trans-mitral flow; E', early mitral annular diastolic movement; E: A, ratio of peak velocity of the trans-mitral flow in early (E) and late (A); E': A', ratio of mitral annular diastolic movement in early (E') and late (A'); E: E', ratio of early peak velocity of the trans-mitral flow and early mitral annular diastolic movement; IVRT, isovolumetric relaxation time; E: IVRT, ratio of early peak velocity of the trans-mitral flow and isovolumetric relaxation time; PVVmáx, peak velocity of the pulmonary valve; AVVmáx, peak velocity of the aortic valve; $\mathrm{S}$, peak velocity of the left myocardial wall measured during systole $(P<0.05)$.

Similar letters are indicative of a lack of differences $(P>0.05)$

$P=0.01$; Fig. 3).

$$
I V R T=62.3+1.8 \times \text { gestational day }-0.08 \times \text { gestational day }{ }^{2}+0.0008 \times \text { gestational day }{ }^{3}
$$

The PVVmáx was similar during anestrus, estrus, and the postpartum period. During gestation, the PVVmáx increased to the $45^{\text {th }}$ day (17\%) and decreased slightly until the $60^{\text {th }}$ day of gestation. This effect was explained by a cubic regression model $\left(R^{2}=0.83\right.$; $P=0.001$; Fig. 4).

$$
\text { PVVmáx }=0.95-0.01 \times \text { gestational day }+0.0006 \times \text { gestational day }{ }^{2}-0.000006 \times \text { gestational day }{ }^{3}
$$

The AVVmáx was similar during anestrus, estrus, postpartum, and gestation, however, there was a slight increase on the $60^{\text {th }}$ when compared to the $15^{\text {th }}$ day of gestation (Fig. 4). The E' (lat) and E' (s) were similar during anestrus, estrus, and the postpartum period $(P>0.05)$. The $E^{\prime}$ (lat) decreased gradually until the $30^{\text {th }}$ day of gestation, and increased between the $45^{\text {th }}$ and $60^{\text {th }}$ day of gestation. This effect was explained by a cubic regression model $\left(R^{2}=0.68 ; P=0.036\right.$; Fig. 5).

$$
E^{\prime} \text { lat }=0,12-0,0013 \times \text { gestational day }+0,00006 \times \text { gestational day }{ }^{2}-0,000001 \times \text { gestational day }{ }^{3}
$$

The $E^{\prime}(s)$ increased gradually during gestation peaking on the $60^{\text {th }}$ day of gestation $(17 \%)$. This effect was explained by a linear 


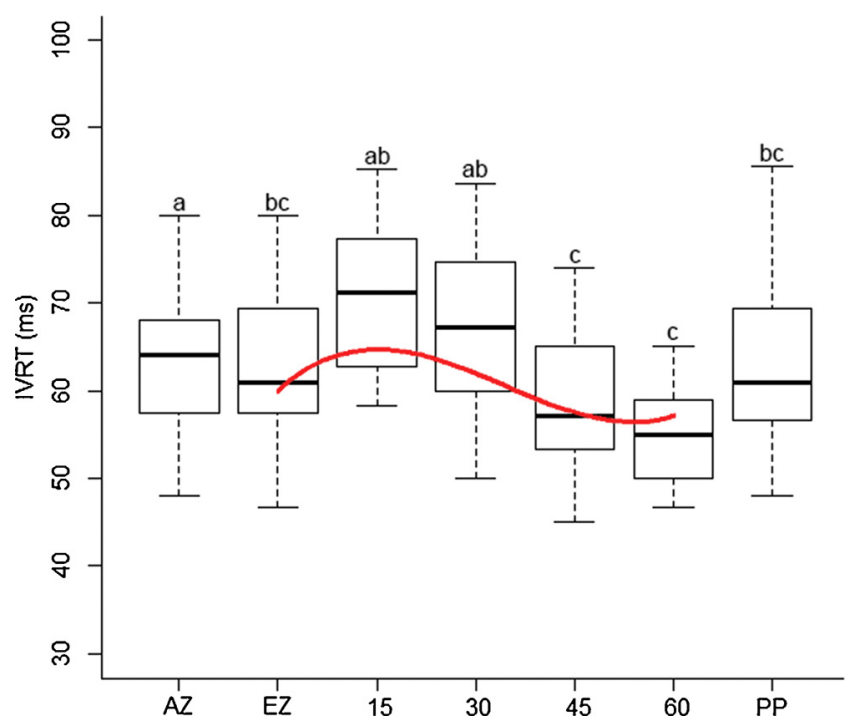

Fig. 3. Graphical representation of isovolumetric relaxation time (IVRT) evaluated in bitches during anestrus (AZ), estrus (EZ), pregnancy days 15, 30, 45 and 60 , and 45 days postpartum (PP). Similar letters are indicative of a lack of differences $(P>0.05)$ and the red line indicates the regression model that estimates the changes in values of these variables during gestation.
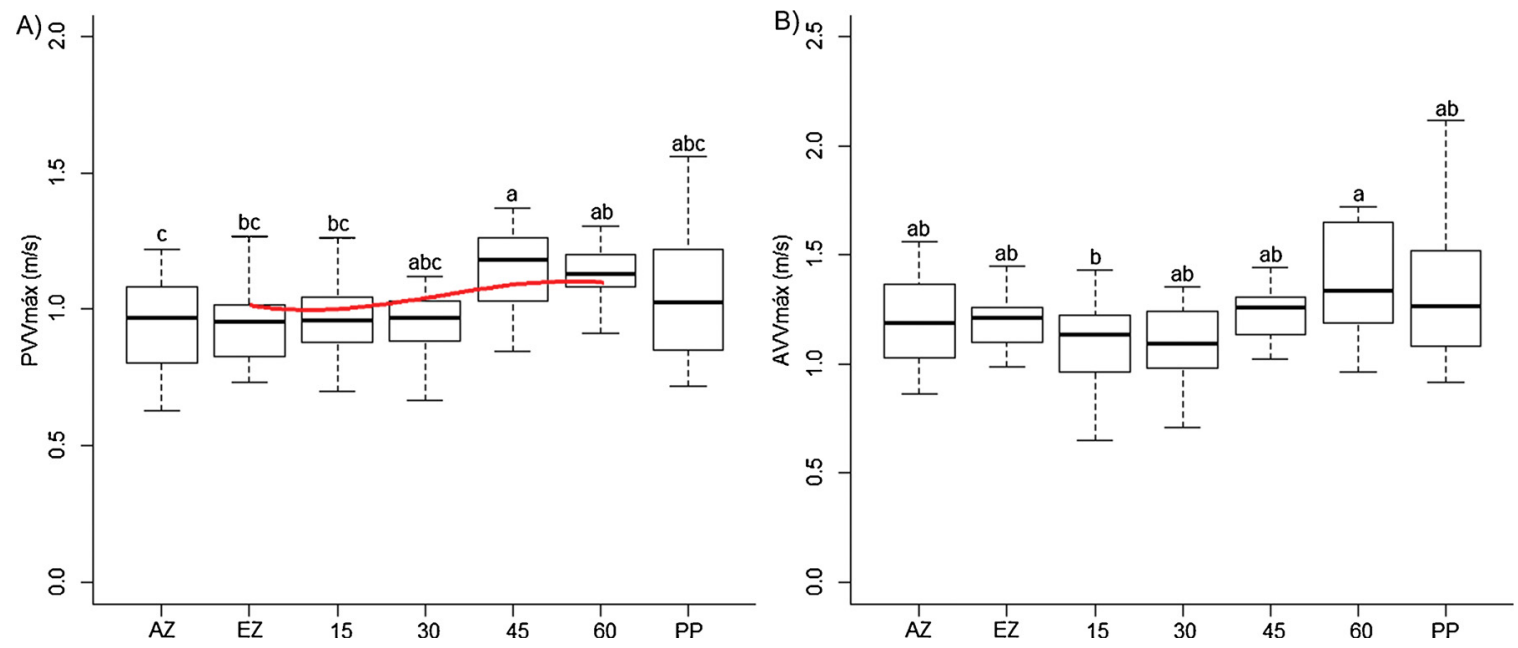

Fig. 4. Graphical representation of: A) peak velocity of the pulmonary valve (PVVmáx); B) peak velocity of the aortic valve (AVVmáx); evaluated in bitches during anestrus (AZ), estrus (EZ), pregnancy days 15, 30, 45 and 60, and 45 days postpartum (PP). Similar letters are indicative of a lack of differences $(P>0.05)$ and the red line indicates the regression model that estimates the values for these variables during gestation.

regression model $\left(R^{2}=0.40, P=0.001\right.$; Fig. 5).

$$
E^{\prime} s=0.1+0.0004 \times \text { gestational day }
$$

The $\mathrm{A}^{\prime}(\mathrm{s})$ was less $(P=0.031)$ during estrus than anestrus, and similar $(P>0.05)$ during the other reproductive phases that variables were assessed. The A' (lat) was similar during estrus, anestrus, and the postpartum period, however, values increased $(P=0.003)$ to the $45^{\text {th }}$ day of gestation (Fig. 5). The $S^{\prime}$ (lat) was less during anestrus than the postpartum period, increasing significantly to the $45^{\text {th }}$ day of gestation (30\%), and subsequently decreasing gradually until the postpartum period. This effect was explained by a cubic regression model $\left(R^{2}=0,70 ; P=0.001 ;\right.$ Fig. 5$)$.

$$
S^{\prime}(\text { lat })=0.11-0.002 \times \text { gestational day }+0.00007 \times \text { gestational day }{ }^{2}-0.000001 \times \text { gestational day }{ }^{3}
$$

The $S^{\prime}(s)$ was similar during anestrus, estrus, and the postpartum period, and there was a decrease $(P=0.012)$ to the $15^{\text {th }}$ and $30^{\text {th }}$ day of gestation when compared to values obtained during anestrus followed by an increase that resulted in values at 45 days of gestation similar to that found in anestrus. (Fig. 5).

The E:E' (s) was similar during anestrus, estrus, and the postpartum period. During gestation, the E:E' (s) gradually decreased $(P=0.035)$ and the least values $(12 \%)$ were observed on the $45^{\text {th }}$ day of gestation (Fig. 6). 

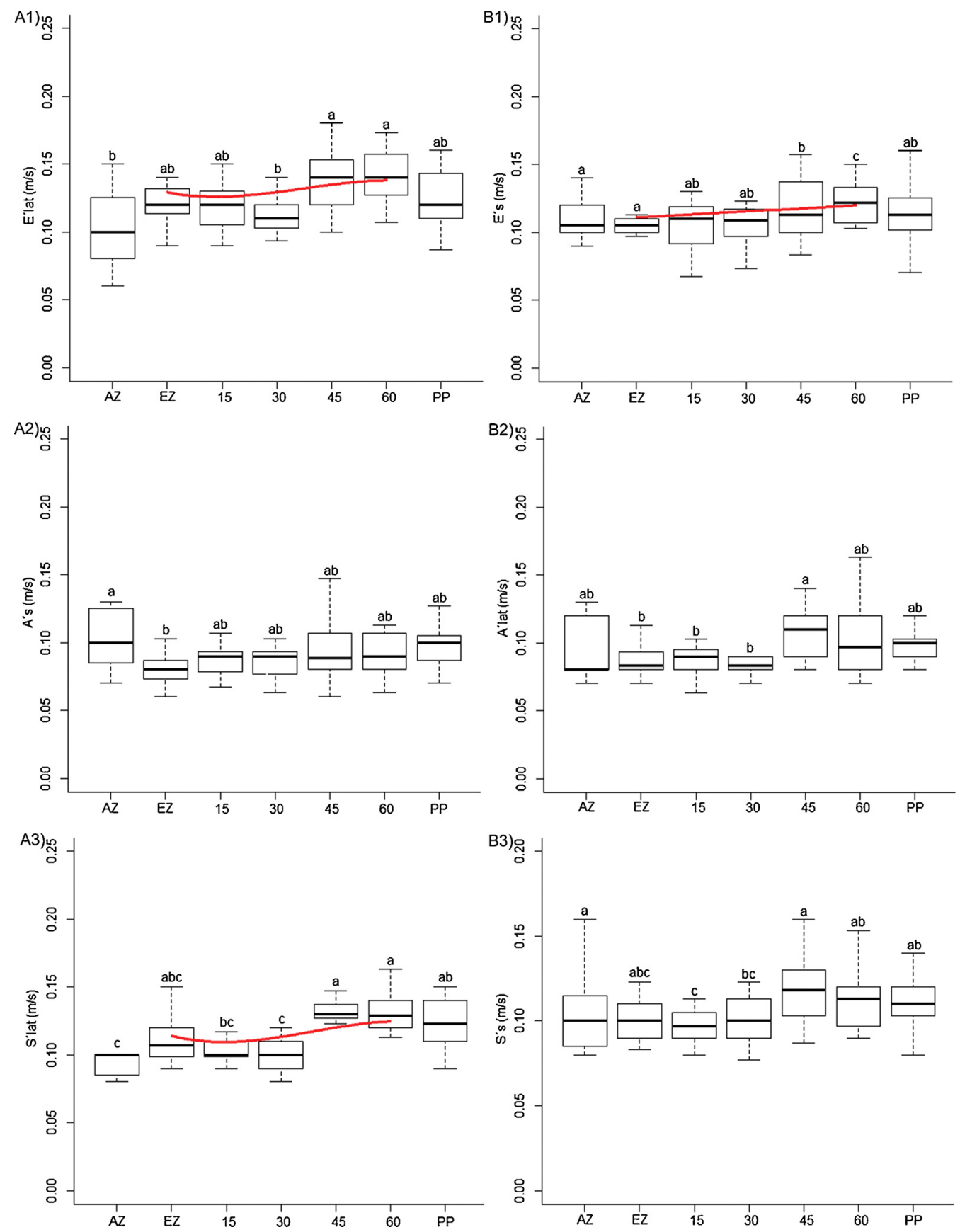

Fig. 5. Graphical representation of diastolic movement determined by tissue Doppler: A1) early mitral lateral annular (E' (lat)); and B1) early mitral septal annular diastolic movement (E' (s)); A2) late mitral septal annular diastolic movement (A' (s)); and B2) late mitral lateral annular diastolic movement (A' (lat)); A3) peak velocity of the left myocardial lateral wall measured during systole by tissue Doppler (S' (lat)); and B3) peak velocity of the left myocardial septal wall (S' (s)); evaluated in bitches during anestrus (AZ), estrus (EZ), pregnancy days 15, 30, 45 and 60, and 45 days postpartum (PP). Similar letters are indicative of a lack of differences $(P>0.05)$ and the red line indicates the values the regression model estimates for these variables during gestation.

\section{Discussion}

The main cardiovascular adaptations during the gestational process in healthy bitches occurred in the last third of gestation, when compared with values during anestrus, estrus and the postpartum period. These changes probably occurred due to a more effective systolic performance and to an increase in ventricular compliance. These results are consistent with findings in previous studies (Abbott, 2010; Blanco et al., 2011; Blanco et al., 2012; Souza et al., 2017).

Heart Rate did not vary and these findings are consistent with those of Souza et al. (2017), where vagal tone was found to 


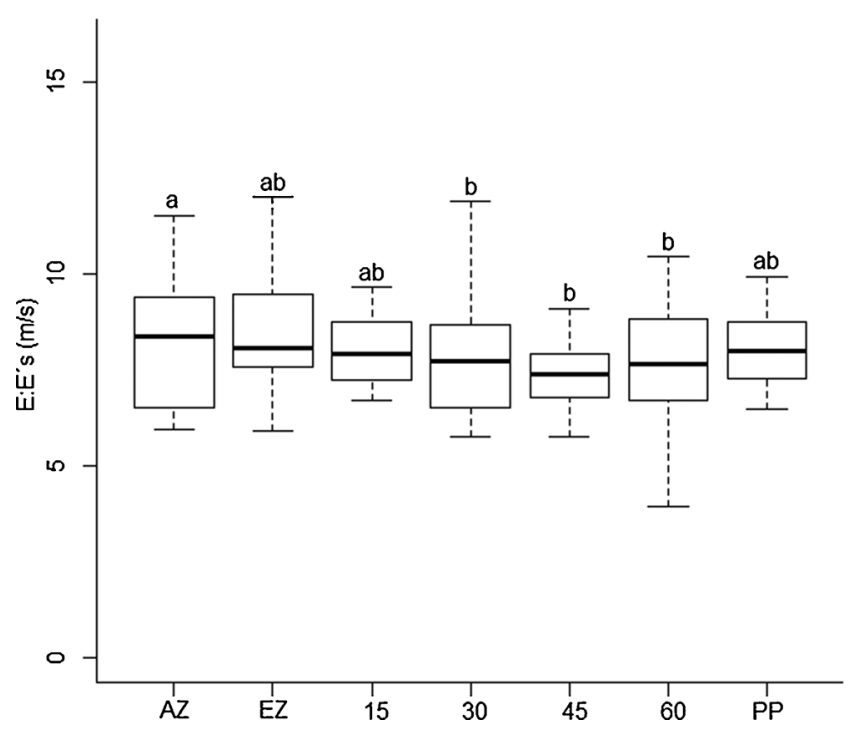

Fig. 6. Graphical representation of the E: E's ratio of the early peak velocity of the trans-mitral flow and early mitral annular diastolic movement determined by tissue Doppler (septal); evaluated in bitches during anestrus (AZ), estrus (EZ), pregnancy days 15, 30, 45, and 60 and 45 days postpartum (PP). Similar letters are indicative of a lack of differences $(P>0.05)$.

downregulate the heart rate in response to an increase in the hemodynamic demand. This response occurs so the heart rate does not increase to harmful rates during gestation and cause damage to the cardiovascular system.

Variables relating to the thickness and diameter of the cardiac chambers were not different when compared among the reproductive stages evaluated in the present study, these findings are consistent with the results of Souza et al. (2017). In contrast in women was reported an physiological hypertrophy of the eccentric type as consequence of hemodynamic overload, when the myocardium adapts by Frank-Starling mechanism (Eghbali et al., 2005; Fok et al., 2006; Patey et al., 2017). Same results were related in previous studies in bitches (Abbott, 2010; Blanco et al., 2012) but without an significant increase in the thickness of the myocardial wall or karyometry analysis which allows them to reach this conclusion (Liberatori Filho et al., 1998). It is therefore inferred that, the absence of myocardial remodeling evidence in bitches is probably due to the shorter gestation length, in which structural changes of the myocardium do not reach the magnitude of those for humans.

The velocities of the pulmonary (PVVmáx) and aortic (AVVmáx) flows were greater during gestation as evidenced by those between the $45^{\text {th }}$ and $60^{\text {th }}$ days of gestation. These findings are consistent with an improvement in systolic function at the end of gestation that was previously reported by Abbott (2010). Another indicator of the improvement in the systolic function during this period was the increase in wave $S^{\prime}$ obtained using the tissue Doppler exam from the $30^{\text {th }}$ to $60^{\text {th }}$ days of gestation. This type of adaptation during the first third of gestation has been reported in women (Bamfo et al., 2007) and reflects contractility increases of the left ventricle which was probably influenced by preload augmentation.

Hemodynamic changes during gestation also affect left ventricular compliance. Structural realignment of myocardial tissue during this phase principally that of the collagen fibers may influence diastolic function. Although the trans-mitral flow analysis results indicated there was a decrease in the E:A ratio in the last third of gestation, the peak velocity of the A and $\mathrm{A}^{\prime}$ waves increased during this same period due to a great influence of atrial contraction, which increases ventricular filling (Fok et al., 2006). Additionally, these waves also increased at the $45^{\text {th }}$ day of gestation relating an increase in the diastolic filling rate and greater ventricular compliance.

The E:E' ratio, which is a marker of left ventricular diastolic pressure (Wu et al., 2008) was less between the $45^{\text {th }}$ and $60^{\text {th }}$ days of gestation, when ventricular relaxation became inadequate for compensation. During this time period, the atrial pressure increased, and the $\mathrm{E}$ wave and E:E' ratio increased (Boon, 2011). In the present study, therefore, the ventricle was more compliant, as verified by E' wave increase and E:E' ratio decrease. The $\mathrm{E}$ wave did not change gradually during gestation, but was greater on the $45^{\text {th }}$ day of gestation, resulting in a lesser ratio during this period with a lesser ventricular pressure being present probably due to a more compliant ventricle.

The values for the IVRT were greater on the 15th of gestation, and this may be a result of a decrease in the ventricular relaxation (Boon, 2011), not necessarily a lesser diastolic filling, but a ventricle that was less compliant. The lesser values at the $45^{\text {th }}$ and $60^{\text {th }}$ days of gestation related an increase in ventricular compliance during the last third of gestation as result of associations with values for other variables.

In conclusion, the healthy gestational process in bitches results in changes in maternal hemodynamics as validated in the present study by associated changes in echocardiography variables when compared with to the other reproductive phases evaluated. During gestation, the myocardial contractility increases resulting in improved systolic efficiency and increased ventricular compliance. By understanding the normal physiological changes that occurred in the present study, it becomes possible to investigate issues involving the pathophysiology of heart disease and its repercussions on gestation. 


\section{Conflict of Interest}

The authors declare that they have no competing interests.

\section{Acknowledgements}

The authors would like to thank FAPESP for the financial support to the research group (processes 2010/16913-7; 2011/06011-9; 2012/16635-2) and Coordenação de Aperfeiçoamento de Pessoal de Nível Superior (CAPES).

\section{References}

Abbott, J.A., 2010. The effect of pregnancy on echocardiographic variables in healthy bitches. J. Vet. Cardiol. 12, $123-128$.

Bamfo, J.E.A.K., Kametas, N.A., Nicolaides, K.H., Chambers, J.B., 2007. Reference ranges for tissue Doppler measures of maternal systolic and diastolic left ventricular function. Ultrasound. Obstet. Gynecol. 29, 414-420.

Blanco, P.G., Arias, D.O., Gobello, C., 2008. Doppler ultrasound in canine pregnancy. J. Ultrasound. Med. 27, 1745-1750.

Blanco, P.G., Arias, D., Rube, A., Barrena, J.P., Corrada, Y., Gobello, C., 2009. An experimental model to study resistance index and systolic/diastolic ratio of uterine arteries in adverse canine pregnancy outcome. Reprod. Domestic. Animals 44, 164-166.

Blanco, P.G., Tórtora, M., Rodríguez, R., Arias, D.O., Gobello, C., 2011. Ultrasonographic assessment of maternal cardiac function and peripheral circulation during normal gestation in dogs. Vet. J. 190, 154-159.

Blanco, P.G., Batista, P.R., Gómez, F.E., Gobello, C., 2012. Echocardiographic and Doppler assessment of maternal cardiovascular function in normal and abnormal canine pregnancies. Theriogenology. 78, 1235-1242.

Boon, J., 1998. The echocardiographic examination. In: J.A, Boon (Ed.), Manual of Veterinary Echocardiography. Media, Williams and Wilkins, pp. 35-128.

Boon, J.A., 2011. Veterinary echocardiography, second ed. Wiley Blackwell, West Sussex.

Chetboul, V., Gouni, V., Sampedrano, C.C., Tissier, R., Serres, F., Pouchelon, J.L., 2007. Assessment of Regional Systolic and Diastolic Myocardial Function Using Tissue Doppler and Strain Imaging in Dogs with Dilated Cardiomyopathy. J. Vet. Intern. Med. 21, 719-730.

Di Salvo, P., Bocci, F., Zelli, R., Polisca, A., 2006. Doppler evaluation of maternal and fetal vessels during normal gestation in the bitch. Res. Vet. Sci. 81, 382-388.

Eghbali, M., Deva, R., Alioua, A., Minosyan, T.Y., Ruan, H., Wang, Y., Toro, L., Stefani, E., 2005. Molecular and functional signature of heart hypertrophy during pregnancy. Circ. Res. 96, 1208-1216.

Feldman, E.C., Nelson, R.W., 2003. In: Saunders, W.B. (Ed.), Canine and feline endocrinology and reproduction, fourth ed. Philadelphia.

Feliciano, M.A.R., Maciel, G.S., Coutinho, L.N., Almeida, V.T., Uscategui, R.R., Vicente, W.R.R., 2015. Gestational echo biometry in brachycephalic pregnant bitches. Ciênc. Anim. Bras 16, 419-427.

Fok, W.Y., Chan, L.Y., Wong, J.T., Yu, C.M., Lau, T.K., 2006. Left ventricular diastolic function during normal pregnancy: assessment by spectral tissue Doppler imaging. Ultrasound. Obstet. Gynecol. 28, 789-793.

Gilson, G.J., Masher, M.D., Conrad, K.P., 1992. Systemic hemodynamics and oxygen transport during pregnancy in chronically instrumented, conscious rats. Am. J. Physiol. 263, 1911-1918.

Liberatori Filho, A.W., Lopes, M.D., Lopes, A.C., 1998. Alterações funcionais do sistema circulatório na gravidez. Rev. Bras. Clin. Terap. 24, $123-127$.

Mucha, C.J., 2001. Eletrocardiografia ambulatorial. In: Belerenian, G., Mucha, C.J., Camacho, A.A. (Eds.), Afecciones cardiovasculares en pequeños animales. Intermedica, Buenos Aires, pp. 33-41.

Nautrup, C.P., 1998. Doppler ultrasonography of canine maternal and fetal arteries during normal gestation. J. Reprod. Fertil. 112, 301-314.

Patey, O., Gatzoulis, M.A., Thilaganathan, B., Julene, S.C., 2017. Perinatal Changes in Fetal Ventricular Geometry, Myocardial Performance, and Cardiac Function in Normal Term Pregnancies. Fetal and Neonatal Echocardiography. J. am. Soc. Echocardiog. 30, 485-492.

Souza, R.C.A., Peres, R., Sousa, M.G., Camacho, A.A., 2017. Cardiac parameters during the estrous cycle of canine bitches. Pesq. Vet. Bras. 37, 295-299.

Wu, W., Wang, H., Tang, Y., Yuan, W., Wang, H., Jiang, Y., 2008. Application of quantitative tissue velocity imaging to evaluate left ventricular early diastolic dysfunction in dogs with heart failure due to rapid ventricular pacing. J. Am. Soc. Echocardiogr. 21, 1269-1276. 